\title{
The research of the noise characteristics including taking-off and landing in the BWB aircrafts
}

\author{
Hui Zhao ${ }^{a}$, Qiushi Li ${ }^{b}$ \\ National Key Laboratory of Science and Technology on Aero-Engine Aero-thermodynamics, \\ Collaborative Innovation Center of Advanced Aero-Engine, School of Energy and Power \\ Engineering, Beihang University, Beijing 100191, China \\ azhaohui.online@163.com, liqs@buaa.edu.cn
}

Keywords: Blended Wing Body, Semi-empirical formula, body's noise, engine noise, Noise prediction.

\begin{abstract}
In this paper, it puts forward and proving an engineering model for the noise forecasting of the BWB aircrafts in the taking-off and landing stage, which is based on the newest semi-empirical model of aerodynamic noise. Such a method could present accurate values of the noise prediction quickly, including taking-off and landing, and be able to estimate or analysis the radiated noise characteristics of the different noise sources. As an example, the detailed noise forecasting results of a new aircraft called "BWB-350" including taking-off and landing are given for introducing the differences between the blended wing body aircrafts and conventional aircrafts. The computational results show that the radiated noise characteristics of the BWB-350 are quite different from the conventional aircrafts. Engine noise always becomes the major noise source and the secondary noise source is body's noise in the BWB-350, whether it's taking-off or landing. And the noise level can be effectively reduced by using the structures called "BWB". Finally, the optimized plan is found through calculating radiated noise levels of various aerodynamic designing plans by using the Semi-empirical method.
\end{abstract}

\section{Introduction.}

In recent years, the air traffic's volumes and the aircraft movements are increasing rapidly [1]. And the contradiction of the low-noise demands is more and more prominent, the noise problem is also one of the frontier problems and technical difficulties in the field of aviation. The best method to control the noise pollution is controlled from the noise sources. Aircrafts' noise prediction is an important research topic in the design of aerodynamic noise. NASA launched the system for predicting the aircrafts noise called “ANOPP” (Aircraft Noise Prediction Program) in the 1980's firstly [2]. And subsequent researches improve and optimize the ANOPP aircraft noise prediction system [3-8]. At present, the conventional aircraft noise is generally up to $90 \mathrm{~dB}$. It can cause a lot of damage to the neighbors, but the BWB aircraft noise can be controlled below $60 \mathrm{~dB}$, because the BWB airplane naturally provides a noise environment, which are lower than the conventional shape, such as jet noise won't be reflected from the wing surface of the regular plane [9-10]. More and more researchers aboard focus on the BWB airplanes hoping to reduce the noise levels through the use of blended-wing-body means. From the early 1990's, the Boeing has started its research about blended-wing- body shape in the technical and commercial. Therefore a rapid, accurate noise prediction method which is suitable for the BWB aircraft is necessary to be put forward.

\section{Models and methods.}

Models. Research shows that the aircraft noise is mainly composed by fan noise, jet noise, wing noise and flap noise. Two assumptions have been made in the noise prediction method. Comparing with the distance of noise dissemination, the aircraft and all kinds of noise sources sizes are treated as infinitesimal, it is considered that all kinds of noise sources are point sources and locating at the midpoint of the aircraft. At the same time, noise attenuation should be considered during the noise 
propagation .That is the first assumption. The second assumption is that the aircraft noise is sum of fan noise, jet noise, wing noise, flap noise and the others. The noise prediction method based on semi-empirical formula could fulfill the engineering requirements. According to the aircraft characteristics, the semi-empirical formula in this paper has been modified by author. Table1 shows the major calculating models of the far-field noise sources.

Table1 The major calculating models of the far-field noise sources

\begin{tabular}{ccc}
\hline & The major calculating models of the far-field noise sources & Notes \\
\hline Noise sources & The calculation of Far-field sound & Basic model \\
\hline Fan & $L_{\varepsilon}=20 \lg \Delta \mathrm{T}+10 \lg G+\sum_{q=1}^{n} F_{\mathrm{q}}$ & Heidmanna model \\
Jet & $\Pi_{T} \approx 2 * 10^{-5} \mathrm{k} \rho_{0} U_{J}{ }^{8} D^{2} C_{0}{ }^{-5}$ & Lighthill model \\
Wing & $O A S P L=50 \lg (v / 100)+10\left(S_{w} / b_{w} / h^{2}\right)$ & \\
& $+8(N D)+10 \lg (\cos \phi \sin \theta \cos \theta / 2)^{2}+104.3 d b$ & Fink model \\
Flap & $O A S P L=112.0+10 \lg \left(S_{F} \sin ^{2} \delta_{F} / h^{2}\right)$ & \\
\hline
\end{tabular}

According to the law of logarithmic in decibels, the total noise level could be described as the following formula.

$$
L_{P T}=10 * \lg \left(\sum_{l=1}^{n} 10^{-1} * L_{r}\right)
$$

\section{Proof}

Because the BWB -350 aircraft is still in the phase of design and there is not enough testing data about the noise. Therefore the B-777, which is similar with BWB-350, is chosen for prove the noise prediction method. The airframe/engine plane parameters and the practical noise values are given by its company website. It was necessary to state that the existing noise literature of the semi-empirical formula is not applicable to the BWB-350.the parameters in the formula should be revised according to the mechanism of the noise generation. Although the wings, fusion segments and the fuselage section together generate the lift, wing areas contain only the wing section and the area of the fusion segments in calculating. The reason is that according to the mechanism of the wing noise, noise is mainly composed of the airfoil wake flow contribution. For the BWB-350, the boundary layers of the fuselage are injected by the engine. The engine jets happen to be the wake of the fuselage, the noise in this part belongs jet noise. The wake flow noise is no longer included in calculating.

Table 2 shows the airframe/engine plane parameters, which are necessary during calculating. Fig1 is the comparison between the noise calculation result and official data of the B-777.

Fig1 shows the noise comparison between calculation result and official data of the B-777. Table 2 Airframe/engine plane parameters

\begin{tabular}{ccc}
\hline & The plane parameters & values(SI) \\
\hline \multirow{3}{*}{ airframe } & Wing area $\left(\mathrm{m}^{2}\right)$ & 465 \\
& Flap area $\left(\mathrm{m}^{2}\right)$ & 60 \\
& Wingspan $(\mathrm{m})$ & 61 \\
& equilibrium field(m) & 2000 \\
\hline \multirow{3}{*}{ engine } & rotor-tip speed(m/s) & 371 \\
& Pressure ratio & 1.4 \\
& Mass $(\mathrm{kg} / \mathrm{s})$ & 1420 \\
\hline
\end{tabular}



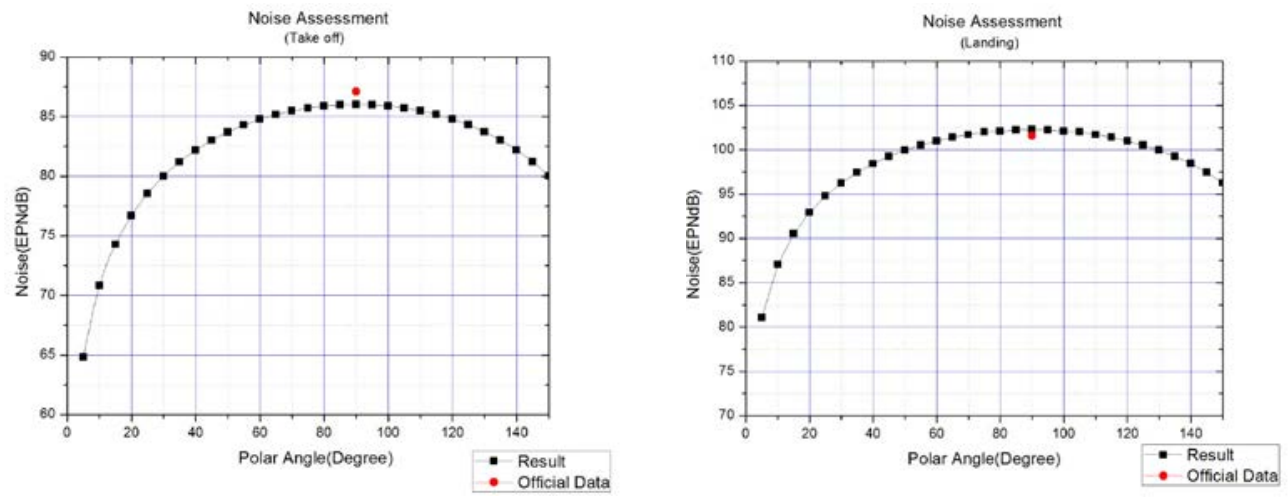

Fig1 the comparison between calculation result and official data of the B-777

From the Fig1, the peak noise value both occurred at the polar Angle in $90^{\circ}$ The Fig1 shows that the errors between the noise prediction and the official data are in good agreement, whether the B-777 airplane is in taking-off or landing. The error value is respectively 1.1EPNdB and $0.7 \mathrm{EPNdB}$ in taking-off and landing, which is in engineering range, the aircraft noise prediction method based on semi-empirical formula could be used to make the engineering noise evaluation for the BWB-350.

\section{Results and discussion}

The research of the noise characteristics. The method used in this part is similar to the calculation method mentioned above.

Table 3 illustrates the initial airframe/engine parameters of the BWB-350 aircraft and the noise prediction result is showed by Fig 2 . Table 4 shows the requirement values of the noise airworthiness.

The noise prediction results are given by the Fig2, Fig3 and Fig4.

Table 3 the airframe/engine plane parameters

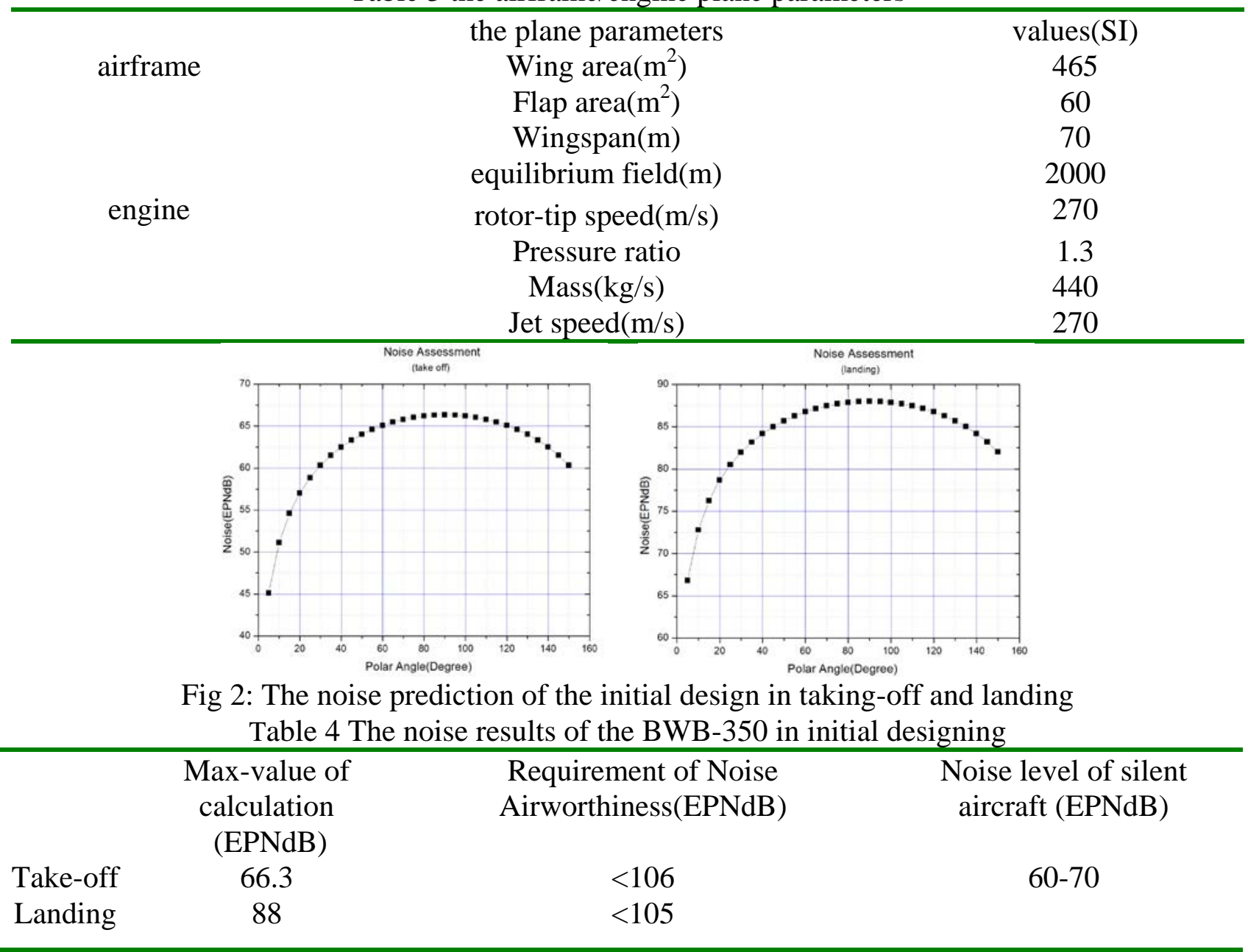


From the table 4, the maximum noise value for the BWB-350 is 66.3 EPNdB in taking-off and 88 EPNdB in landing, which is far lower than the requirement of noise airworthiness. Compared with the Boeing 777-200, 20.3 EPNdB and 13.6 EPNdB are decreased. At the same time, according to the noise level of the silent aircraft, BWB-350 also has reached the standard in the take-off stage. The aircraft noise felt by ears is less than the background noise in the airport.

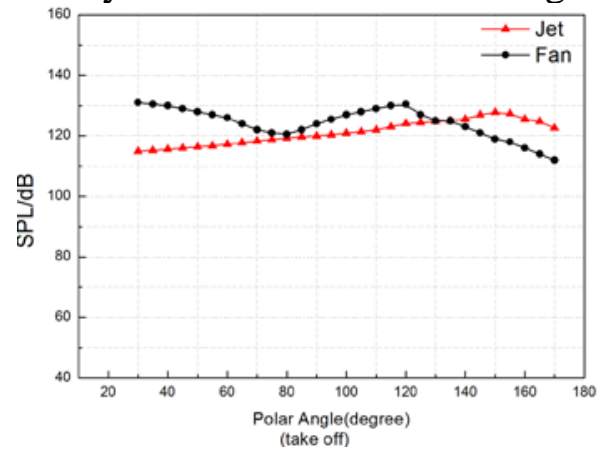

(a)Engine noise

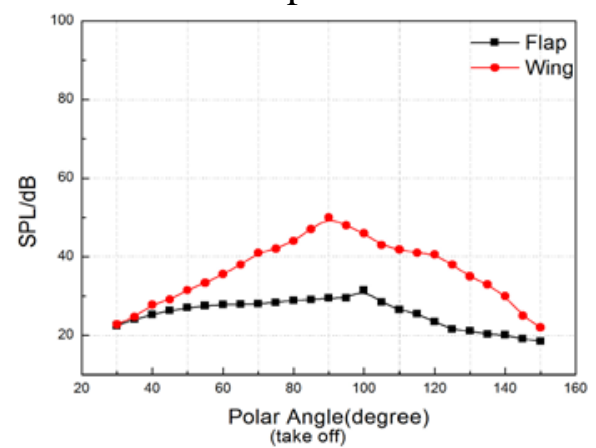

(b)Body noise

Fig3: The characteristics of the different noise sources in taking-off

There were obvious differences in the radiated characteristics of different noise sources. For the fan noise the max-value occurs at the polar angle from $30^{\circ}$ to $120^{\circ}$. For the jet noise, the max-value occurs at the polar angle in $150^{\circ}$.the peak noise value of the wing noise occurs at $90^{\circ}$ and the flap noise is at $100^{\circ}$.

For the BWB-350 aircraft, representing the blended wing body aircrafts, the fan noise and jet noise become the major noise whether the aircraft is in taking-off or landing. Meanwhile the airframe noise also could not be ignored.

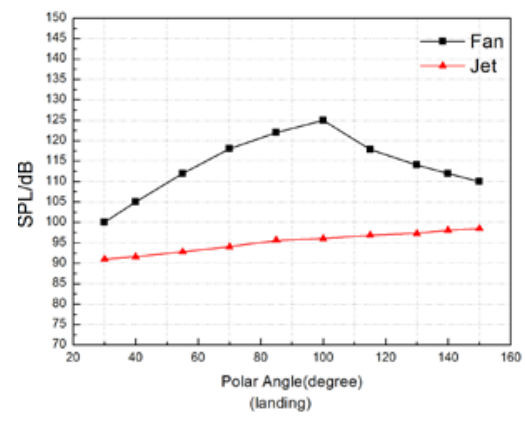

(a)Engine noise

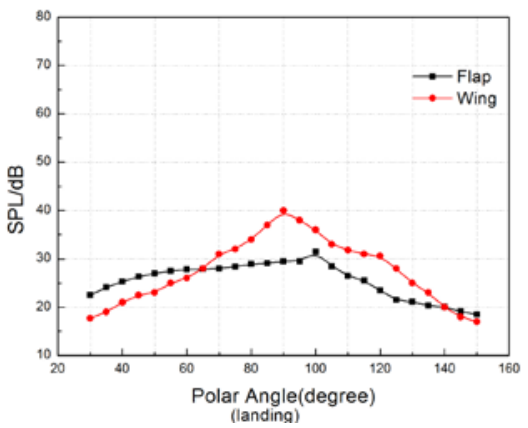

(b)Body noise

Fig4: The characteristics of the different sources in landing

Engineering application. During the design processes, except noise control, the performance of the airplane's structure and aerodynamic design must be guaranteed. There are five kinds of design plans which could meet the basic design demands. Therefore, the best design plan should be found and it will be determined by the other performance index, such as noise value. The method of the noise prediction research's significance lies that through calculating the aircraft noise of the different working states, the aircraft design process will be guided quickly and exactly.

Table 5 the designing parameters of the five case

\begin{tabular}{cccccc}
\hline plane parameters & plan A & plan B & plan C & plan D & plan E \\
\hline rotor-tip speed(m/s) & 320 & 271 & 264 & 244 & 230 \\
Pressure ratio & 1.25 & 1.32 & 1.4 & 1.5 & 1.6 \\
Mass $(\mathrm{kg} / \mathrm{s})$ & 540 & 440 & 370 & 320 & 275 \\
Jet speed(m/s) & 196 & 220 & 244 & 270 & 292 \\
\hline
\end{tabular}

Considering the performance and economy, five design cases have been calculated to find out the optimal scheme.

Table 5 shows the designing parameters of the five case and the numerical simulation results have been given in Fig 5. With the change of the aerodynamic designs, the noise level has larger changes, which ranges from the $65 \mathrm{EPNdB}$ to $73 \mathrm{EPNdB}$.the best design plan could be chosen by Fig 5 quickly. 


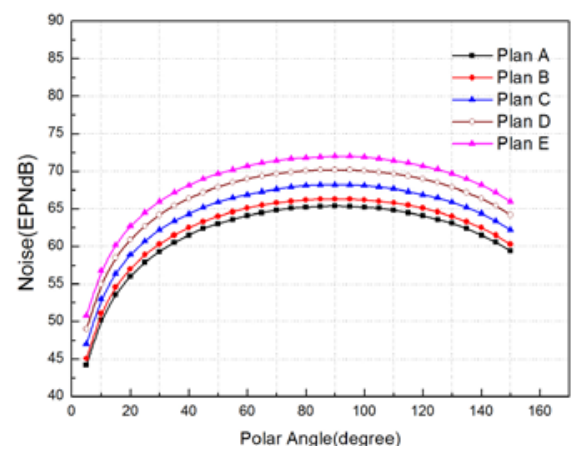

Fig 5: the noise predictions results of five design plans

\section{Conclusions}

The developed noise prediction method is been proposed and testified, which is suitable for blended wing body aircrafts in taking-off and landing. This method is based on the newest semi-empirical model of aerodynamic noise and the semi-empirical formula in this paper has been modified.

For the BWB aircrafts, the observation points on the ground are affected by the different noise sources and the influence depends on the relative position between the source and the point. Compared with the ordinary aircrafts, the airframe noise could be reduced effectively by the structure of blended wing body. The fan noise and jet noise become the major noise whether the aircraft is in taking-off or landing. Meanwhile, the airframe noise also could not be ignored.

The technique has great significance in predicting aircraft noise in the course of designing. The noise levels of the different noise sources and the aircrafts in taking-off or landing could be calculated quickly and relatively accurately.

The best noise design could be chosen quickly. Therefore, the method can save cost, keep satisfactory in quality, meet performance requirement, and shorten its designing cycle.

\section{References}

[1]Tang Diyi, Li Wenlan, Qiao Weiyang. The elements of air-craft noise [M]. Xi'an: Northwestern Polytechnical University Press, 1995. (In Chinese).

[2]Zorumski W E. Aircraft noise prediction program[R].NASA TM-83199, 1982.

[3]Gustavo D F, Joao R B. Analysis of turbofan empirical noise prediction methods [R]. AIAA -2005-3076, 2005.

[4]Baralon S, Eriksson L E, Billson M. Evaluaiton of advance prediction methods for aero engine exhaust noise [R] ISABE-2005-1190, 2005.

[5]Kontos K B, Janardan B A, Gliebe P R. Improve NASA-ANOPP noise prediction computer code for advanced subsonic propulsion systems, Volume 1:ANOPP evaluation and fan noise model improvement [R]. NASA CR 195480, 1966.

[6]Rawls J W, Yeager J C. High speed research noise prediction code (HSRNOISE) [R]. NASA CR-2004-213014, 2004.

[7]Lieber L. Small engine technology (SET)-Task 13 ANOPP noise prediction for small engines (jet noise prediction module, wing shielding module, and system studies results) [R]. NASA CR-2000-209706, 2000.

[8]Lieber L, Elkins D.Small engine technology(SET)-Task 33 final report airframe, integration, and community noise study [R]. NASA CR-2002-211670, 2002.

[9]Zhu Ziqiang, Wang Xiaolu, Wu zongcheng,et al, Multidisciplinary optimization and numerical simulations in civil aircraft design [J]. Acta Aeronautica et Astronautica Sinica, 2007, 27(1): p. 1-13.(In chinese).

[10]Smith H. College of aeronautics blended wing body development programme [R]. ICAS 20001.1.4, 2000. 